Check for updates

Cite this: Soft Matter, 2018, 14,8838

Received 12th June 2018,

Accepted 10th October 2018

DOI: $10.1039 / \mathrm{c} 8 \mathrm{sm} 01199 \mathrm{k}$

rsc.li/soft-matter-journal

\section{Extensional flow behaviour and spinnability of native silk $\dagger$}

\author{
Andreas Koeppel, (D) Peter R. Laity (D) and Chris Holland (D) *
}

\section{Introduction}

Natural silk spinning is a highly energy efficient process, creating protein fibres with an impressive combination of stiffness, strength and elasticity comparable to, and often exceeding, that of synthetic polymers. ${ }^{1-5}$ These properties are attributed to the self-assembly of hierarchical structures present in silk fibres ${ }^{6,7}$ which are not only the result of protein sequence but also the way the feedstock is processed, ${ }^{8,9}$ i.e. spun. ${ }^{10}$

Understanding and successfully replicating natural silk spinning can hopefully pave the way for a new generation of high performance low embodied energy materials. ${ }^{11} \mathrm{~A}$ recent systematic review of artificial silk fibre spinning by our group quantitatively assessed 49 studies over the past 70 years, ${ }^{12}$ revealing that current artificial spinning approaches are yet to match as-spun natural fibres and in order to do so require non-natural spinning conditions (i.e. harsh solvents) or significant post processing (i.e. post spin draw). ${ }^{12-16}$ We concluded that to produce a truly biomimetic silk requires the field to both develop improved (i.e. higher molecular weight) ${ }^{17}$ artificial feedstocks and in tandem, spinning systems that replicate the flow conditions and chemistry present in the natural spinning duct.

Natural silk spinning begins with an aqueous native protein feedstock secreted at high concentration $(\sim 400 \mathrm{kDa}$ at $\sim 250 \mathrm{mg} \mathrm{ml}^{-1}$ or $25 \%$ dry weight) into specialised glands. ${ }^{10,18}$

Department of Materials Science and Engineering, University of Sheffield,

Mappin Street, Sheffield S1 3JD, UK. E-mail: christopher.holland@sheffield.ac.uk

$\dagger$ Electronic supplementary information (ESI) available: Details and results of surface tension measurements. Extensional flow videos. The datasets generated for this study are available in the University of Sheffield's Online Research Data Archive (ORDA) repository, 10.15131/shef.data.6402095. See DOI: 10.1039/ c8sm01199k
As the feedstock is pulled through the gland, ${ }^{19}$ the silk proteins in both spiders and silkworms experience changes in $\mathrm{pH},{ }^{20-23}$ metal ion content, ${ }^{8,24,25}$ and become aligned due to flow stress ${ }^{26,27}$ before finally forming a solid fibre as they undergo extensional flow. ${ }^{19,27,28}$ While the physiological changes during natural spinning are well understood, little is known about how silk proteins respond to a purely extensional flow field.

This is an important gap in our knowledge as control of extensional flow fields has been shown to be crucial in successfully designing fibre spinning devices in both polymer and biopolymer-based systems. ${ }^{16,29-32}$ This was first seen by Chappel and co-workers ${ }^{33}$ in 1964 when they were trying to spin Nylon 6.6 and today with a range of groups across the world who are looking at how extensional flow imparts orientation and structure development during melt processing and especially in fibre spinning. ${ }^{34-39}$

For silk, extensional flow has been hypothesised to provide uniaxial stretching of a liquid silk feedstock, resulting in a stress-induced alignment, denaturation, crystallisation, aggregation and fibrillation to form a solid fibre. ${ }^{28,40}$ However, in practice this has been difficult to explore due to historic difficulties in creating a purely uniaxial flow field, let alone applying it to milligram sized samples. ${ }^{29}$

The challenges associated in creating instruments to measure extensional flow properties became evident in the M1 study in 1990 where various methods for measuring the extensional properties of a standardised test fluid were compared (including a spinline rheometer, ${ }^{41}$ opposing jets ${ }^{42,43}$ and a converging flow rheometer $\left.{ }^{44}\right) .{ }^{45}$ The different setups revealed huge differences in measuring extensional properties of the M1 fluid as they suffered from drawbacks such as unknown pre-shear history, inability to measure steady state conditions and non-ideal extensional 
flow fields. ${ }^{45,46}$ With testing native silk in mind, it was found the most promising method for small sample amounts was developed by Matta and Tytus who used a falling cylinder device which achieved the best approximation to ideal extensional deformation. ${ }^{45,47}$ This setup was later developed into the widely used filament stretching device by Sridhar and Tirtaatmadja which allows a nearly ideal uniaxial extension. ${ }^{48,49}$

Another widely used method akin to this is the capillary break-up extensional rheometer (CaBER) which is based on works by Entov and co-workers. ${ }^{50,51}$

Both filament stretching and CaBER methods are now well established and have been applied primarily to characterise dilute and semi-dilute polymer solutions, ${ }^{29,52-67}$ worm-like micelle solutions ${ }^{64,68-70}$ and other biopolymers such as cellulose which are relevant for fibre spinning. ${ }^{71-73}$

However, whilst the CaBER setup lends itself very well to more dilute polymer solutions and Newtonian fluids, ${ }^{61,74}$ filament stretching offers the potential to obtain extensional properties of higher viscosity fluids such as polymer melts, ${ }^{75}$ making it more suitable for testing native silks.

Over a decade of shear rheology has shown native silk extracted directly from the animal's silk gland behaves like a concentrated and entangled protein solution (now referred to as an aquamelt). ${ }^{11,76-81}$ However, whilst the shear flow behaviour of silk is largely understood, its extensional flow is not, having only begun to be addressed in a single study by Kojic and co-workers over a decade ago. ${ }^{82}$ In that study they reported extensional properties by stretching a native spider silk protein sample extracted from the major ampullate gland in a customised microscale capillary break-up extensional rheometer. However, due to limited sample availability and an estimation of surface tension, the resulting extensional properties may not be entirely representative of the natural system.

Therefore, our study seeks to extend this knowledge by investigating fibre formation of native silk proteins extracted from the silkworm Bombyx mori under extensional flow fields.

To achieve this we have developed, as suggested by Kojic et al., ${ }^{82}$ a filament stretching rheometer ${ }^{48}$ as a means to investigate the extensional properties of small sample sizes with high viscosity ${ }^{46}$ and determined the surface tension of native silk (which is also important for other silk-water interactions ${ }^{83}$ such as electrospinning ${ }^{84}$ and printing ${ }^{85}$ ).

\section{Experimental methods}

\section{Native silk preparation}

Native silk proteins were obtained from the silk gland of fifth instar Bombyx mori silkworms and prepared as previously described. ${ }^{77}$ In brief, silkworms were dissected and their glands carefully removed and transferred into a Petri dish containing distilled water. The epithelium was peeled off with fine tweezers under a dissection microscope (SZ40, Olympus, Japan) and the gland contents were subsequently washed again in distilled water.

All experiments were conducted using native silk proteins extracted from the posterior part of the middle section of the silk gland which have a concentration of $24.0 \pm 2.5 \mathrm{wt} \% .^{77}$ This part of the gland is predominantly free of sericin, ensuring that silk fibroin is the main component tested. ${ }^{86,87}$

\section{Surface tension of native silk fibroin}

The surface tension of native silk fibroin was measured according to the sessile bubble method previously reported by Andrade and Nakamura. ${ }^{88,89}$ In brief, native silk proteins were very gently spread on the flat surface of an aluminium stub with the help of a glass slide. Special care was taken to apply as little shearing as possible to the silk proteins and to obtain a level surface. The aluminium stub was then submerged in water and an air bubble was placed on the silk surface with the help of a micro glass capillary (Fig. 1).

Assuming all three phases (silk, water and air) are in equilibrium the Young's equation for the surface tension of silk can be calculated as:

$$
\gamma_{\mathrm{SA}}=\gamma_{\mathrm{SW}}+\gamma_{\mathrm{WA}} \cos \left(\theta_{\mathrm{A}}\right)
$$

where $\theta_{\mathrm{A}}$ is the contact angle (Fig. 1). The subscripts S, A and W refer to the phases silk, air and water (and later O refers to oil). The combination of two subscripts, for example SW, refers to the interfacial tension, in this case silk and water. When air is the second phase (i.e. SA, WA, OA), the subscript refers to the surface tension of the first phase. Accordingly, the interfacial tension between silk and water can be calculated from their polar and dispersive surface tension components by applying the harmonic mean approximation:

$$
\gamma_{\mathrm{SW}}=\gamma_{\mathrm{SA}}+\gamma_{\mathrm{WA}}-4\left(\frac{\gamma_{\mathrm{SA}}^{\mathrm{d}} \gamma_{\mathrm{WA}}^{\mathrm{d}}}{\gamma_{\mathrm{SA}}^{\mathrm{d}}+\gamma_{\mathrm{WA}}^{\mathrm{d}}}\right)-4\left(\frac{\gamma_{\mathrm{SA}}^{\mathrm{p}} \gamma_{\mathrm{WA}}^{\mathrm{p}}}{\gamma_{\mathrm{SA}}^{\mathrm{p}}+\gamma_{\mathrm{WA}}^{\mathrm{p}}}\right) .
$$

By replacing the air bubble with an oil droplet which is not soluble in water and silk, two further equations characterising the silk-oil interfacial properties can be deduced:

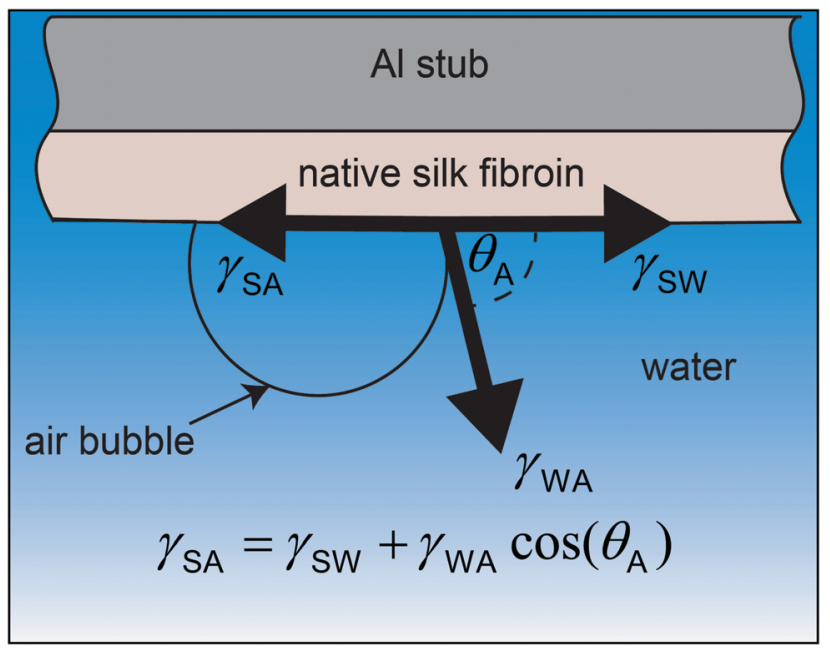

Fig. 1 Air bubble placed on a native silk fibroin surface which was carefully spread on an aluminium stub and submerged in water. The equilibrium state between the surface tension of water $\left(\gamma_{\mathrm{WA}}\right)$, silk $\left(\gamma_{\mathrm{SA}}\right)$ and their interfacial tension $\left(\gamma_{s w}\right)$ allows the formulation of the Young's equation. 


$$
\begin{gathered}
\gamma_{\mathrm{SO}}=\gamma_{\mathrm{SW}}+\gamma_{\mathrm{WO}} \cos \left(\theta_{\mathrm{O}}\right) \\
\gamma_{\mathrm{SO}}=\gamma_{\mathrm{SA}}+\gamma_{\mathrm{OA}}-4\left(\frac{\gamma_{\mathrm{SA}}^{\mathrm{d}} \gamma_{\mathrm{OA}}^{\mathrm{d}}}{\gamma_{\mathrm{SA}}^{\mathrm{d}}+\gamma_{\mathrm{OA}}^{\mathrm{d}}}\right)-4\left(\frac{\gamma_{\mathrm{SA}}^{\mathrm{p}} \gamma_{\mathrm{OA}}^{\mathrm{p}}}{\gamma_{\mathrm{SA}}^{\mathrm{p}}+\gamma_{\mathrm{OA}}^{\mathrm{p}}}\right)
\end{gathered}
$$

The superscripts $\mathrm{d}$ and $\mathrm{p}$ describe the dispersive and polar surface tension components.

Combining eqn (1)-(4) yields two eqn (5) and (6) that allow the calculation of the surface tension components of silk $\left(\gamma_{\mathrm{SA}}^{\mathrm{d}}\right.$ and $\left.\gamma_{\mathrm{SA}}^{\mathrm{P}}\right)$ and hence the total surface tension of silk $\left(\gamma_{\mathrm{SA}}=\gamma_{\mathrm{SA}}^{\mathrm{d}}+\gamma_{\mathrm{SA}}^{\mathrm{P}}\right)$.

Equation 5 and 6 have been simplified as the polar component of oil is negligible so that $\gamma_{\mathrm{OA}}^{\mathrm{P}}=0$ :

$$
\begin{aligned}
& \gamma_{\mathrm{SA}}^{\mathrm{d}}\left(\frac{\gamma_{\mathrm{WA}}^{\mathrm{d}}}{\gamma_{\mathrm{SA}}^{\mathrm{d}}+\gamma_{\mathrm{WA}}^{\mathrm{d}}}-\frac{\gamma_{\mathrm{OA}}^{\mathrm{d}}}{\gamma_{\mathrm{SA}}^{\mathrm{d}}+\gamma_{\mathrm{OA}}^{\mathrm{d}}}\right)+\gamma_{\mathrm{SA}}^{\mathrm{p}}\left(\frac{\gamma_{\mathrm{WA}}^{\mathrm{p}}}{\gamma_{\mathrm{SA}}^{\mathrm{p}}+\gamma_{\mathrm{WA}}^{\mathrm{p}}}\right) \\
& =\frac{\gamma_{\mathrm{OW}} \cos \left(\theta_{\mathrm{O}}\right)+\gamma_{\mathrm{WA}}-\gamma_{\mathrm{OA}}}{4} \\
& \gamma_{\mathrm{SA}}^{\mathrm{d}} \frac{\gamma_{\mathrm{WA}}^{\mathrm{d}} \gamma_{\mathrm{SA}}^{\mathrm{d}}+\gamma_{\mathrm{WA}}^{\mathrm{d}}}{\gamma_{\mathrm{SA}}}+\gamma_{\gamma_{\mathrm{SA}}^{\mathrm{p}}+\gamma_{\mathrm{WA}}^{\mathrm{p}}}^{\mathrm{p}}=\frac{\gamma_{\mathrm{WA}}^{\mathrm{p}}\left[1+\cos \left(\theta_{\mathrm{A}}\right)\right]}{4}
\end{aligned}
$$

The contact angles of the oil droplet $\theta_{\mathrm{O}}$ and air bubble $\theta_{\mathrm{A}}$ to the silk surface were determined with an ImageJ plugin by analysing their shape. ${ }^{90}$ The surface tension of water $\left(\gamma_{\mathrm{WA}}=72.8 \mathrm{mN} \mathrm{m}^{-1}\right)$ and its polar and dispersive components $\left(\gamma_{\mathrm{WA}}^{\mathrm{d}}=21.8 \mathrm{mN} \mathrm{m}^{-1}\right.$, $\gamma_{\mathrm{WA}}^{\mathrm{p}}=51 \mathrm{mN} \mathrm{m}^{-1}$ ) were taken from literature. ${ }^{91}$ The surface tension of oil as well as the interfacial tension of the water-oil system were determined via the pendant drop method (see ESI $\dagger$ ).

\section{Filament stretching}

A conventional Zwick Z0.5 testing machine (Zwick GmbH \& Co. $\mathrm{KG}$, Germany) equipped with a $5 \mathrm{~N}$ load cell was modified into a filament stretching device and used to determine the extensional properties of native silk fibroin (Fig. 2a). ${ }^{29,48,49}$ Around $5 \mathrm{mg}(\sim 6 \mu \mathrm{l})$ of native protein was sandwiched between two parallel plates which were then separated exponentially from their initial gap $L_{0}$ (Fig. 2b) to a maximum length of $20 \mathrm{~mm}$ according to the following equation:

$$
L(t)=L_{0} \mathrm{e}^{\dot{\varepsilon}_{0} t}
$$

where $\dot{\varepsilon}_{0}$ is the constant strain rate for ideal extension. During stretching, the force was recorded by the load cell of the Zwick and the evolution of the mid-diameter of the filament was recorded by a $1.45 \mathrm{MP}$ QICAM 12-bit Mono camera (QImaging, Canada) at a rate of 10 frames per second (see Fig. 2c). The middiameter is used to determine the effective extension rate $\dot{\varepsilon}_{\text {eff }}$ :

$$
\dot{\varepsilon}_{\text {eff }}=\frac{-2}{D_{\mathrm{m}, 0}} \frac{\mathrm{d} D_{\mathrm{m}}(t)}{\mathrm{d} t}
$$

which is a function of time and compensates for the non-ideal extensional flow field caused by the no-slip boundary at the endplates. ${ }^{29,92}$ The Hencky strain $\varepsilon_{\text {eff }}$ can then be calculated by:

$$
\varepsilon_{\mathrm{eff}}=-2 \ln \left(\frac{D_{\mathrm{m}}(t)}{D_{\mathrm{m}, 0}}\right)
$$

with the help of a force balance derived by Szabo, the tensile stress difference of the silk filament can be determined. ${ }^{93}$

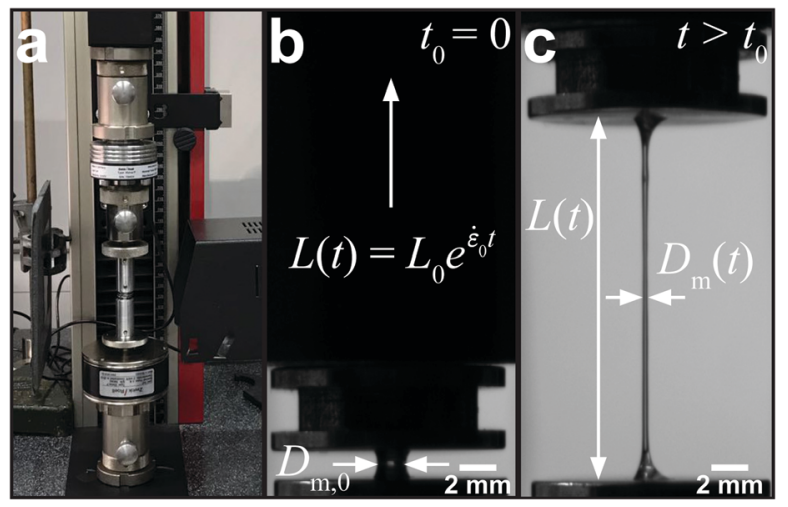

Fig. 2 Setup and evaluation of the filament stretching experiment. (a) A conventional Zwick Z0.5 testing machine was modified for filament stretching. (b) Initial plate separation prior to starting the test. The plates were then separated according to an exponential profile. (c) The force and filament mid-diameter were recorded for each experiment which permits the calculation of the transient extensional viscosity with an effective extension rate.

Due to the high viscosity of the silk feedstock, the low amount of sample used and the short stretching length at low extension rates, gravitational and inertial effects can be negated in our case. ${ }^{49}$ The tensile stress difference in the filament can therefore be calculated by:

$$
\left\langle\tau_{z z}-\tau_{r r}\right\rangle=\frac{F(t)}{\left(\pi D_{\mathrm{m}}^{2}(t) / 4\right)}-\frac{\sigma}{\left(D_{\mathrm{m}}(t) / 2\right)}
$$

where $F(t)$ is the force recorded with the load cell of the tensile tester and $D_{\mathrm{m}}(t)$ is the mid-diameter of the filament. The surface tension, $\sigma$, was determined by the method described above. Dividing the tensile stress difference by the effective extension rate yields the transient extensional viscosity $\eta_{\mathrm{E}}^{+}$:

$$
\eta_{\mathrm{E}}^{+}=\frac{\left\langle\tau_{z z}-\tau_{r r}\right\rangle}{\dot{\varepsilon}_{\mathrm{eff}}}
$$

The silk proteins were uniaxially stretched under standard lab conditions $\left(23 \pm 1{ }^{\circ} \mathrm{C}, 50 \pm 5 \% \mathrm{RH}\right)$ at rates varying from 0.05 to $0.5 \mathrm{~s}^{-1}$. Of particular note is that the exponential profiles of the highest rates $\left(0.3\right.$ and $\left.0.5 \mathrm{~s}^{-1}\right)$ are equivalent to spinning speeds between $5-10 \mathrm{~mm} \mathrm{~s}^{-1}$, replicating those used by the silkworm in nature. ${ }^{94,95}$

For extensional tests in a high humidity atmosphere, an environmental chamber was built around the sample in situ which was then filled with saturated water vapour created by a humidifier. The humidity inside the chamber was measured with a TRH 22 hygrometer (Meterman, UK).

\section{Shear rheology experiments}

Shear rheology experiments were performed on a Bohlin Gemini rheometer (Malvern Instruments, UK) with a CP1/10 cone and plate geometry $\left(10 \mathrm{~mm}\right.$ diameter, $1^{\circ}$ opening angle and $30 \mu \mathrm{m}$ truncation) at $25{ }^{\circ} \mathrm{C}$. Details of sample loading and handling are reported in detail elsewhere. ${ }^{77,79}$

Experiments were performed in three stages. At first, a conditioning step was applied at a shear rate of $1 \mathrm{~s}^{-1}$ for 
$100 \mathrm{~s}$ to equally distribute the sample in the geometry and eliminate any residual stresses from loading. Second, oscillatory measurements were performed from 25 to $0.1 \mathrm{~Hz}$ at an applied strain of 0.02 . Lastly, the shear viscosity was determined by applying a shear rate ramp from $0.1 \mathrm{~s}^{-1}$ to $100 \mathrm{~s}^{-1}$. The value for the zero-shear viscosity $\eta_{0}$ was determined by extrapolation of the viscosity curve to $0 \mathrm{~s}^{-1}$.

\section{Results and discussion}

\section{Surface tension of native silk}

As stated previously and evidenced by eqn (10), extensional force is clearly influenced by surface tension and therefore should be determined experimentally prior to conducting filament stretching. To achieve this, results for the contact angle measurements of an air bubble and oil droplet on a silk surface and the resulting surface tension of silk and its polar and dispersive components are shown in (Fig. 3a-c).

From these tests the surface tension of native silk was found to range between 43.3 and $69.1 \mathrm{mN} \mathrm{m}^{-1}$, with an average of $54.2 \mathrm{mN} \mathrm{m}^{-1}$. Any inter-sample variability (see Table S2, ESI $\dagger$ ) was attributed to minor differences in concentration, surface roughness and timing. However despite this variation, our results are in agreement with the range from 30 to $60 \mathrm{mN} \mathrm{m}^{-1}$ that was estimated by Kojic and co-workers ${ }^{82}$ and those measured previously for a reconstituted silk ${ }^{96}$ (a process by which spun silk fibres are rehydrated using chaotropic agents). ${ }^{80}$

\section{Extensional flow behaviour and spinnability of native silk}

Native silk proteins were stretched at different rates to evaluate their extensional flow behaviour and subsequent spinnability (ability to form fibres, see video 1). From initial observations during stretching, silk proteins were observed to be prone to necking in the middle of the fluid column. This process is initiated by shear forces acting on the fluid at small strains as a result of the material adhering to the endplates. ${ }^{49,52}$ Despite this necking, samples showed good spinnability at the lowest rates $\left(0.05 \mathrm{~s}^{-1}\right.$ and $\left.0.1 \mathrm{~s}^{-1}\right)$ as they could always be stretched out into fibres up to a plate separation of $20 \mathrm{~mm}$.

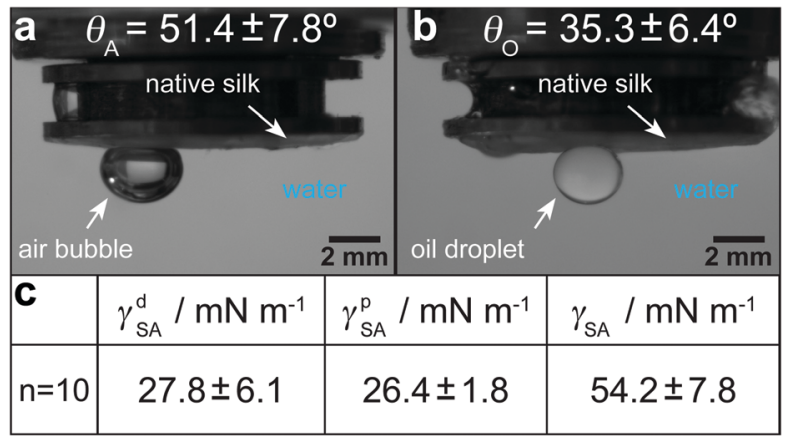

Fig. 3 Results for the surface tension of silk. (a) Contact angle of air bubbles to the silk surface. (b) Contact angle of oil droplets to the silk surface. (c) Polar and dispersive components and total surface tension of native silk. The results for all 10 measurements are shown in Table S2 (ESI $\dagger$ ).
Upon increasing the extension rate, filament formation became less likely at $0.2 \mathrm{~s}^{-1}$ and impossible $>0.3 \mathrm{~s}^{-1}$ (video 1 , ESI $\dagger$ and Fig. 4a). From video 1 (ESI $\dagger$ ) it is clear that these filaments did not fail due to continuous necking but snapped instantly due to elastic fracture. We interpret this as when subjected to higher extension rates the silk proteins cannot either relax/rearrange in time to the deformation field or lack sufficient stiffness (gel strength) and therefore the fluid column ruptures due to the build-up of elastic stresses. This is surprising as these higher extension rates coincide with natural spinning speeds (see $\mathrm{ESI} \dagger$ ). Therefore, there may be factors other than extensional flow contributing to natural fibre formation at higher rates that are not accounted for here and will be the subject of future work.

Regardless of filament formation, the extensional flow behaviour of the silk proteins could still be evaluated by determining the transient extensional viscosity $\left(\eta_{\mathrm{E}}^{+}\right)$. When plotted against time, three distinct regions can be identified in the viscosity curve for all extension rates (Fig. 4b): after an initial transient response, the viscosity plateaus before it deviates upwards. The viscosity increase after the plateau arises from an effect called strain hardening, which is shifted to shorter times for higher extension rates. For the animal this appears fortuitous as strain hardening is an important property in polymers that improves processability during fibre spinning by stabilising the fluid column and reducing necking. ${ }^{97,98}$

Assuming the silk feedstock to be akin to an entangled polymer solution, ${ }^{76}$ we attribute the observed strain hardening and associated viscosity increase to be due to chain entanglements hindering the rearrangement of the silk proteins during flow. ${ }^{55,75,99}$

The extent of strain hardening can be compared for the different extension rates by eliminating the time factor and plotting the transient extensional viscosity against the total Hencky strain $\varepsilon_{\text {eff }}$ (Fig. 4c). Starting from a Hencky strain of 1 all curves show strain hardening with similar slopes up to a value of $10^{5} \mathrm{~Pa} \mathrm{~s}$, suggesting that the viscosity increase is independent of the tested strain rates. Our measurements of silkworm silk fibroin shows less pronounced strain hardening when compared to Kojic's spider silk which reaches viscosity values above $10^{6} \mathrm{~Pa}$ s for a Hencky strain of $3 .^{82}$ Although spider and silkworm silks differ markedly in molecular structure, this order of magnitude difference may also due to the small sample size and therefore the influence of dehydration in the previous work. $^{82}$

Therefore, to estimate the influence of dehydration during our extensional experiments, we determined the processability parameter $P$, a dimensionless number that relates the stretching time with the time scale of water diffusion (limits water evaporation) through the native silk dope $\left(P=t_{\text {stretch }} / t_{\text {diff }}\right) .{ }^{82,100,101}$ Water evaporation is negligible for $P \ll 1$ but becomes significant for values approaching 1 . At the start of our extensional experiments where the diameter is around $1 \mathrm{~mm}$, evaporation is negligible yet might have an influence at smaller diameters towards the end of the experiment. Consequently, we analysed the influence of water evaporation starting from the point where the filament has a diameter of $100 \mu \mathrm{m}$. The time scale for diffusion is given 


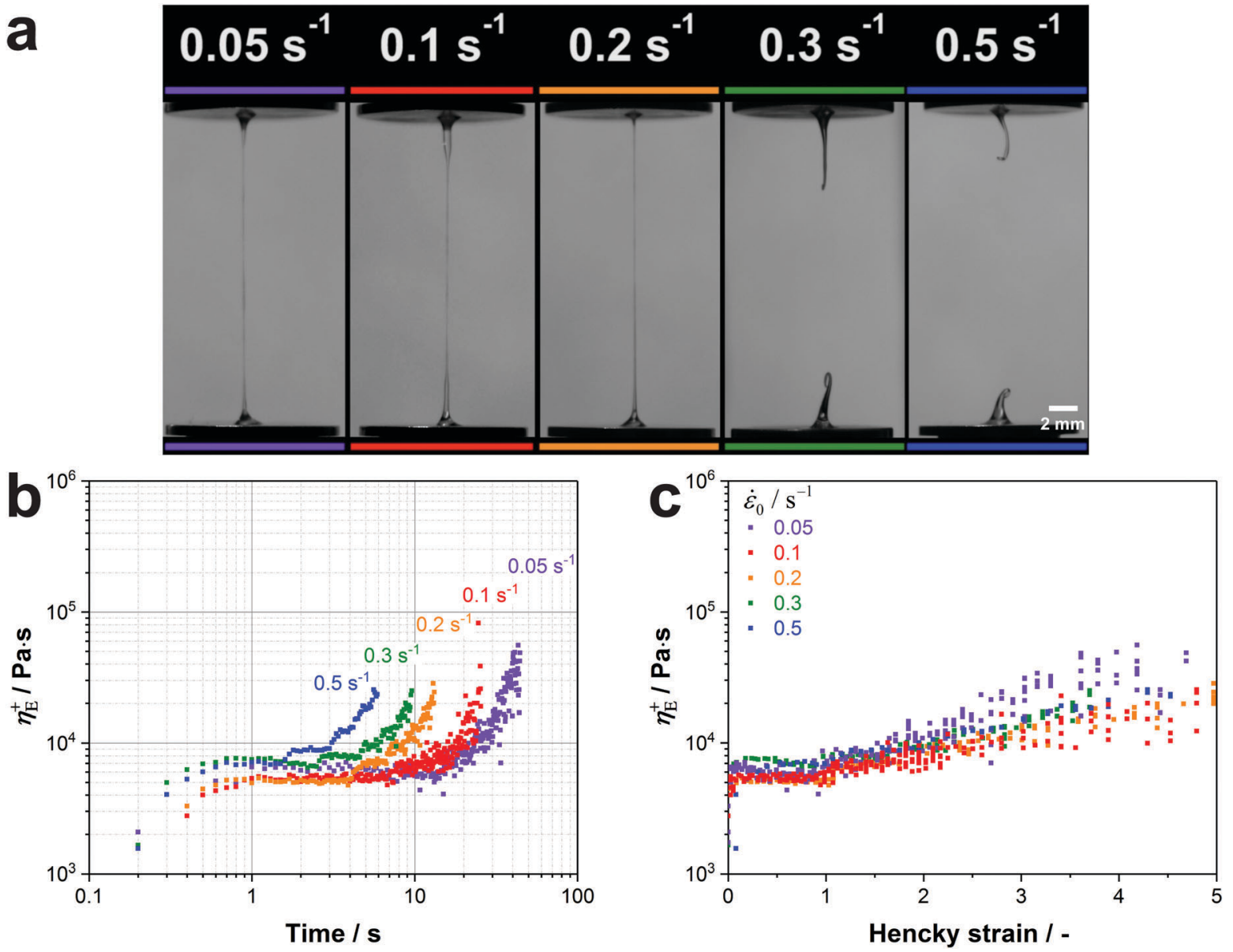

Fig. 4 (a) Native silk proteins show a good spinnability at low extension rates while no stable fibre formation is possible at speeds which are characteristic for natural silk spinning. (b) Transient extensional viscosity of silk fibroin for different extension rates plotted against time. (c) Transient extensional viscosity plotted against the Hencky strain $\varepsilon_{\text {eff }}$ to eliminate the time factor and compare the strain hardening behaviour for the different extension rates. It was found that $\eta_{E}^{+}$in the plateau region is subjected to a high variability between different worms. This variability was already found in shear rheology experiments from our group. ${ }^{77}$ As proteins from different worms were used for each extension rate, we compared curves with similar extensional viscosities in the plateau region (5000-7500 Pa s).

by $t_{\text {diff }}=R / D_{\mathrm{w}}$, where $R$ is the initial filament radius $(100 \mu \mathrm{m}$ in our case) and $D_{\mathrm{w}}$ the diffusivity for water in silk $\left(D_{\mathrm{w}}=\right.$ $\left.2 \times 10^{-5} \mathrm{~mm}^{2} \mathrm{~s}^{-1}\right) .{ }^{82,102}$

For 0.3 and $0.5 \mathrm{~s}^{-1}$ the stretching time $t_{\text {stretch }}$ from a filament diameter of $100 \mu \mathrm{m}$ to the end of the test (in this case filament rupture) is around $1 \mathrm{~s}$, which results in a processability parameter of $P \leq 0.008$. This suggests a negligible influence of water evaporation during stretching at high extensional rates. Towards lower extension rates, the stretching time increases and the processability value $P$ returns values of 0.12 for $0.1 \mathrm{~s}^{-1}$ and 0.24 for $0.05 \mathrm{~s}^{-1}$. These values indicate that at low extension rates filament dehydration becomes a significant influence.

These results were confirmed by stretching our native protein samples in a water saturated atmosphere $(98 \% \mathrm{RH})$ at $0.1 \mathrm{~s}^{-1}$ (see video 2, ESI $\dagger$ ). Although the proteins exhibited the same transient extensional viscosity increase under both conditions, it was not possible to form a fibre in a high humidity atmosphere as the fluid column continuously necked backwards (see video 2 and Fig. 5a).
Consequently, we conclude that the strain hardening behaviour is evoked by the entangled structure of silk and is only influenced by water evaporation starting from a Hencky strain of around 4-5. This suggests that fibre formation at low extension rates is only possible due to dehydration at the final stage of stretching, when the diameter gets smaller than $\sim 20 \mu \mathrm{m}$.

Another factor thought to have considerable influence on fibre spinning is the shear viscosity of the dope. ${ }^{103}$ It is known from previous publications that despite having a similar concentration of fibroin in the posterior middle gland $(24.0 \pm$ $2.5 \mathrm{wt} \%)$, the shear viscosity of Bombyx mori silk is highly variable and thought to be controlled mainly by the ratio of $\mathrm{Ca}^{2+}$ to $\mathrm{K}^{+}$ions. ${ }^{77,104}$ Therefore, to determine the relationship between shear and extensional responses in silk, and to compare to other polymers, we performed both experiments on samples from the same silk gland and calculated the transient Trouton ratio $\mathrm{Tr}^{+}=\eta_{\mathrm{E}}^{+} / \eta_{0}$.

At the extremes of the natural zero shear viscosity range for silk ( $\sim 3500 \mathrm{~Pa}$ s), we found it was not possible to stretch samples in a consistent manner due to inconsistent necking. 

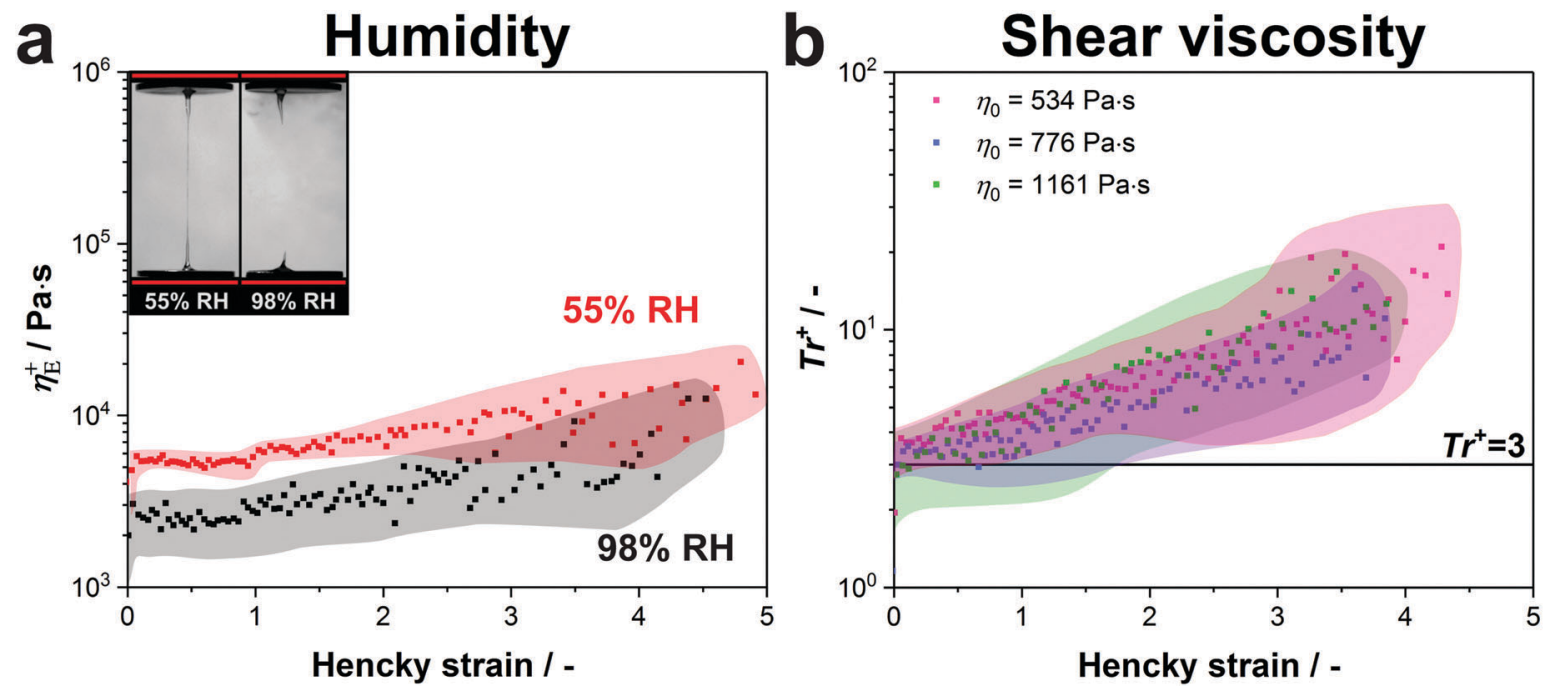

Fig. 5 (a) The transient extensional viscosity of native silk proteins is compared at standard lab conditions ( $55 \%$ RH) and in a water saturated atmosphere $(98 \% \mathrm{RH})$. Three samples for both conditions were measured and the curves were averaged. The coloured area around the data points shows the standard deviation. (b) Transient Trouton ratio over Hencky strain for native silk samples with various zero-shear viscosities. Although the tested protein samples have slightly different concentrations (534 Pa s: 19.6 wt\%, $776 \mathrm{~Pa} \mathrm{s:} 20.2$ wt\% and $1161 \mathrm{~Pa} \mathrm{s:} 22.1$ wt\%), the main cause for the variation in zeroshear viscosity is the metal ion composition of the silk proteins. ${ }^{104}$ Five samples were measured for each viscosity and the curves were averaged. The coloured area around the data points shows the standard deviation.

At zero shear viscosities of $2500 \mathrm{~Pa}$ s and below, silk's response to stretching was markedly improved, becoming much more uniform.

Fig. 5b depicts the transient Trouton ratios for native silk protein samples with zero-shear viscosities within the natural range $^{77}(<1500 \mathrm{~Pa}$ s, shear responses may be seen in Fig. S2, ESI $\dagger)$.

All curves show three characteristic regions (transient startup, plateau and strain hardening) as previously discussed. As seen from Fig. 5b, the Trouton ratio in the plateau region (Hencky strains smaller than 1) approaches values close to 3, which is consistent with the ratio Trouton found in 1906 for Newtonian fluids. ${ }^{105}$ However, this finding also holds for viscoelastic fluids, such as silk fibroin, for very low extension rates. ${ }^{106}$ The transient Trouton ratio further increases and reaches values of around 20 at a Hencky strain of 4 , with all samples showing the same strain hardening behaviour. When these numbers are compared to other polymer systems, they are much lower than dilute polymers where Trouton ratios can reach several hundred or even exceed several thousand, ${ }^{54,68}$ but higher than entangled linear polymer melts such as high density polyethylene (HDPE) or linear low density polyethylene (LLDPE) which do not, or only marginally show, strain hardening. ${ }^{55}$ Instead, the silk samples display Trouton ratios comparable to branched molecules such as low density polyethylene (LDPE). ${ }^{75}$

To explain this, we must consider the molecular structure of silk. B. mori silk feedstock's primarily protein component, $\mathrm{H}$-fibroin, is a linear polypeptide chain consisting of highly repetitive GAGAGS domains and non-repetitive regions including the $\mathrm{N}$ - and C-terminals that consist mainly of charged and polar side groups. ${ }^{107}$ Hence together with hydrogen bonding between repetitive domains and polar side groups, salt bridges between charged side groups could act as physical crosslinks that create an additional hindrance in removing molecular entanglements during extension, accounting for silk's increased strain hardening compared to other linear polymers. ${ }^{104}$

\section{Conclusions}

Our study investigates the extensional flow properties and spinnability of native silk feedstock. By adapting a conventional tensile tester into a filament stretching rheometer, we demonstrate it is possible to test the spinnability of various high viscosity fluids, in our case silk, in a reliable way. This technique also provides us with new insight into the response of native silk proteins to extensional flow conditions, which to date has yet to be fully explored but is immensely important if we are to fully understand natural fibre formation.

Our results show that the native silk feedstock exhibits a surprisingly high degree of strain hardening for a linear protein solution which is rather comparable to branched entangled polymers. We suggest that silk's unusual extensional behaviour may be attributed to a high degree of interchain interactions formed by salt bridges.

Yet despite strain hardening, which makes silk intrinsically suited for spinning, fibre formation is only possible at low extension rates due to dehydration. At higher spinning speeds which are characteristic for the natural spinning process, the fluid column ruptures and fibres cannot be formed. This suggests that extensional flow alone is not sufficient to create fibres at natural spinning speeds and physiological changes such as $\mathrm{pH}$ and metal ion concentration are required in order to improve the spinnability of silk. 


\section{Conflicts of interest}

There are no conflicts to declare.

\section{Acknowledgements}

The authors would like to thank Carl Reynolds, David M. Hoyle and Richard Thompson for initial tests and discussions as well as Francesca Atkinson for proofreading the manuscript. This study was funded by the EPSRC (EP/K005693/1) and the European Union's Horizon 2020 research and innovation programme under grant agreement no. 713475.

\section{References}

1 T. Asakura and D. Kaplan, Encyclopedia of agricultural science, 1994, 4, 1-11.

2 H. Heslot, Biochimie, 1998, 80, 19-31.

3 F. Vollrath, D. Porter and C. Holland, Soft Matter, 2011, 7, 9595-9600.

4 J. M. Gosline, P. A. Guerette, C. S. Ortlepp and K. N. Savage, J. Exp. Biol., 1999, 202, 3295-3303.

5 A. R. Bunsell, Handbook of tensile properties of textile and technical fibres, Elsevier, 2009.

6 S. Keten, Z. Xu, B. Ihle and M. J. Buehler, Nat. Mater., 2010, 9, 359-367.

7 D. Porter and F. Vollrath, Adv. Mater., 2009, 21, 487-492.

8 M. Andersson, J. Johansson and A. Rising, Int. J. Mol. Sci., 2016, 17, 8.

9 T. Lefèvre, S. Boudreault, C. Cloutier and M. Pézolet, Biomacromolecules, 2008, 9, 2399-2407.

10 F. Vollrath and D. Porter, Polymer, 2009, 50, 5623-5632.

11 C. Holland, F. Vollrath, A. J. Ryan and O. O. Mykhaylyk, Adv. Mater., 2012, 24, 105-109.

12 A. Koeppel and C. Holland, ACS Biomater. Sci. Eng., 2017, 3, 226-237.

13 F. Zhang, Q. Lu, X. Yue, B. Zuo, M. Qin, F. Li, D. L. Kaplan and X. Zhang, Acta Biomater., 2015, 12, 139-145.

14 G. Zhou, Z. Shao, D. P. Knight, J. Yan and X. Chen, Adv. Mater., 2009, 21, 366-370.

15 X.-X. Xia, Z.-G. Qian, C. S. Ki, Y. H. Park, D. L. Kaplan and S. Y. Lee, Proc. Natl. Acad. Sci. U. S. A., 2010, 107, 14059-14063.

16 J. Luo, L. Zhang, Q. Peng, M. Sun, Y. Zhang, H. Shao and X. Hu, Int. J. Biol. Macromol., 2014, 66, 319-324.

17 C. H. Bowen, B. Dai, C. J. Sargent, W. Bai, P. Ladiwala, H. Feng, W. Huang, D. L. Kaplan, J. M. Galazka and F. Zhang, Biomacromolecules, 2018, 19, 3853-3860.

18 T. Asakura, K. Umemura, Y. Nakazawa, H. Hirose, J. Higham and D. Knight, Biomacromolecules, 2007, 8, 175-181.

19 J. Sparkes and C. Holland, Nat. Commun., 2017, 8, 594.

20 C. W. P. Foo, E. Bini, J. Hensman, D. P. Knight, R. V. Lewis and D. L. Kaplan, Appl. Phys. A: Mater. Sci. Process., 2006, 82, 223-233.
21 C. Dicko, F. Vollrath and J. M. Kenney, Biomacromolecules, 2004, 5, 704-710.

22 L. J. Domigan, M. Andersson, K. A. Alberti, M. Chesler, Q. Xu, J. Johansson, A. Rising and D. L. Kaplan, Insect Biochem. Mol. Biol., 2015, 65, 100-106.

23 Y.-X. He, N.-N. Zhang, W.-F. Li, N. Jia, B.-Y. Chen, K. Zhou, J. Zhang, Y. Chen and C.-Z. Zhou, J. Mol. Biol., 2012, 418, 197-207.

24 D. P. Knight and F. Vollrath, Naturwissenschaften, 2001, 88, 179-182.

25 L. Zhou, X. Chen, Z. Shao, Y. Huang and D. P. Knight, J. Phys. Chem. B, 2005, 109, 16937-16945.

26 C. Viney, Supramol. Sci., 1997, 4, 75-81.

27 F. Vollrath and D. P. Knight, Nature, 2001, 410, 541-548.

28 D. P. Knight, M. M. Knight and F. Vollrath, Int. J. Biol. Macromol., 2000, 27, 205-210.

29 G. H. McKinley and T. Sridhar, Annu. Rev. Fluid Mech., 2002, 34, 375-415.

30 J. J. Rogalski, C. W. M. Bastiaansen and T. Peijs, Nanocomposites, 2017, 3, 97-121.

31 J. Cheng, Y. Jun, J. Qin and S.-H. Lee, Biomaterials, 2017, 114, 121-143.

32 R. S. Lenk, Polymer rheology, Springer Science \& Business Media, 2012.

33 F. P. Chappel, M. F. Culpin, R. G. Gosden and T. G. Tranter, J. Appl. Chem., 1964, 14, 12-19.

34 J. A. Paten, S. M. Siadat, M. E. Susilo, E. N. Ismail, J. L. Stoner, J. P. Rothstein and J. W. Ruberti, ACS Nano, 2016, 10, 5027-5040.

35 J. M. Samon, J. M. Schultz, B. S. Hsiao, S. Seifert, N. Stribeck, I. Gurke and C. Saw, Macromolecules, 1999, 32, 8121-8132.

36 N. Tian, W. Zhou, K. Cui, Y. Liu, Y. Fang, X. Wang, L. Liu and L. Li, Macromolecules, 2011, 44, 7704-7712.

37 E. E. Bischoff White, H. Henning Winter and J. P. Rothstein, Rheol. Acta, 2012, 51, 303-314.

38 J. M. Samon, J. M. Schultz, B. S. Hsiao, J. Wu and S. Khot, J. Polym. Sci., Part B: Polym. Phys., 2000, 38, 1872-1882.

39 J. L. White and M. Cakmak, Adv. Polym. Technol., 1986, 6, 295-337.

40 J. Sparkes and C. Holland, Macromol. Biosci., 2018, DOI: 10.1002/mabi.201800229.

41 D. M. Binding, D. M. Jones and K. Walters, J. NonNewtonian Fluid Mech., 1990, 35, 121-135.

42 T. Schweizer, K. Mikkelsen, C. Cathey and G. Fuller, J. Non-Newtonian Fluid Mech., 1990, 35, 277-286.

43 H. M. Laun and R. Hingmann, J. Non-Newtonian Fluid Mech., 1990, 35, 137-157.

44 D. F. James, G. M. Chandler and S. J. Armour, J. NonNewtonian Fluid Mech., 1990, 35, 421-443.

45 T. Sridhar, J. Non-Newtonian Fluid Mech., 1990, 35, 85-92.

46 S. L. Anna, G. H. McKinley, D. A. Nguyen, T. Sridhar, S. J. Muller, J. Huang and D. F. James, J. Rheol., 2001, 45, 83-114.

47 J. Matta and R. Tytus, J. Non-Newtonian Fluid Mech., 1990, 35, 215-229. 
48 T. Sridhar, V. Tirtaatmadja, D. A. Nguyen and R. K. Gupta, J. Non-Newtonian Fluid Mech., 1991, 40, 271-280.

49 V. Tirtaatmadja and T. Sridhar, J. Rheol., 1993, 37, 1081-1102.

50 A. V. Bazilevsky, V. M. Entov and A. N. Rozhkov, Third European Rheology Conference and Golden Jubilee Meeting of the British Society of Rheology, Springer Netherlands, Dordrecht, 1990.

51 V. M. Entov and E. J. Hinch, J. Non-Newtonian Fluid Mech., 1997, 72, 31-53.

52 S. H. Spiegelberg, D. C. Ables and G. H. McKinley, J. NonNewtonian Fluid Mech., 1996, 64, 229-267.

53 S. H. Spiegelberg and G. H. McKinley, J. Non-Newtonian Fluid Mech., 1996, 67, 49-76.

54 R. K. Gupta, D. A. Nguyen and T. Sridhar, Phys. Fluids, 2000, 12, 1296-1318.

55 G. H. McKinley, O. Brauner and M. Yao, Korea-Australia Rheology Journal, 2001, 13, 29-35.

56 P. K. Bhattacharjee, J. P. Oberhauser, G. H. McKinley, L. G. Leal and T. Sridhar, Macromolecules, 2002, 35, 10131-10148.

57 J. P. Rothstein and G. H. McKinley, J. Rheol., 2002, 46, 1419-1443.

58 J. P. Rothstein and G. H. McKinley, J. Non-Newtonian Fluid Mech., 2002, 108, 275-290.

59 S. L. Anna and G. H. McKinley, Rheol. Acta, 2008, 47, 841-859.

60 T. R. Tuladhar and M. R. Mackley, J. Non-Newtonian Fluid Mech., 2008, 148, 97-108.

61 M. I. Kolte and P. Szabo, J. Rheol., 1999, 43, 609-625.

62 O. Arnolds, H. Buggisch, D. Sachsenheimer and N. Willenbacher, Rheol. Acta, 2010, 49, 1207-1217.

63 L. E. Rodd, T. P. Scott, J. J. Cooper-White and G. H. McKinley, Appl. Rheol., 2005, 15, 12-27.

64 E. Miller, C. Clasen and J. P. Rothstein, Rheol. Acta, 2009, 48, 625-639.

65 C. Clasen, J. P. Plog and W.-M. Kulicke, J. Rheol., 2006, 50, 849-881.

66 J. Plog, W. Kulicke and C. Clasen, Appl. Rheol., 2005, 15, 28-37.

67 J. Dinic, Y. Zhang, L. N. Jimenez and V. Sharma, ACS Macro Lett., 2015, 4, 804-808.

68 A. Bhardwaj, E. Miller and J. P. Rothstein, J. Rheol., 2007, 51, 693-719.

69 M. Chellamuthu and J. P. Rothstein, J. Rheol., 2008, 52, 865-884.

70 B. Yesilata, C. Clasen and G. H. McKinley, J. Non-Newtonian Fluid Mech., 2006, 133, 73-90.

71 S. J. Haward, V. Sharma, C. P. Butts, G. H. McKinley and S. S. Rahatekar, Biomacromolecules, 2012, 13, 1688-1699.

72 V. Sharma, S. J. Haward, J. Serdy, B. Keshavarz, A. Soderlund, P. Threlfall-Holmes and G. H. McKinley, Soft Matter, 2015, 11, 3251-3270.

73 S. Morozova, P. W. Schmidt, A. Metaxas, F. S. Bates, T. P. Lodge and C. S. Dutcher, ACS Macro Lett., 2018, 7, 347-352.

74 G. H. McKinley and A. Tripathi, J. Rheol., 2000, 44, 653-670.

75 A. Bach, H. K. Rasmussen and O. Hassager, J. Rheol., 2003, 47, 429-441.

76 P. Laity and C. Holland, Int. J. Mol. Sci., 2016, 17, 1812.
77 P. R. Laity, S. E. Gilks and C. Holland, Polymer, 2015, 67, 28-39.

78 P. R. Laity and C. Holland, Eur. Polym. J., 2017, 87, 519-534.

79 P. R. Laity and C. Holland, Biomacromolecules, 2016, 17, 2662-2671.

80 C. Holland, A. E. Terry, D. Porter and F. Vollrath, Polymer, 2007, 48, 3388-3392.

81 M. Boulet-Audet, A. E. Terry, F. Vollrath and C. Holland, Acta Biomater., 2014, 10, 776-784.

82 N. Kojic, J. Bico, C. Clasen and G. H. McKinley, J. Exp. Biol., 2006, 209, 4355-4362.

83 A. Renault, J.-F. Rioux-Dubé, T. Lefèvre, S. Beaufils, V. Vié, F. Paquet-Mercier and M. Pézolet, Langmuir, 2013, 29, 7931-7938.

84 B. Singh, N. Panda and K. Pramanik, Int. J. Biol. Macromol., 2016, 87, 201-207.

85 P. M. Rider, I. M. Brook, P. J. Smith and C. A. Miller, Micromachines, 2018, 9, 2.

86 H. Akai, Experientia, 1983, 39, 443-449.

87 J. Machida, Proc. Imp. Acad., 1926, 2, 421-422.

88 J. D. Andrade, S. M. Ma, R. N. King and D. E. Gregonis, J. Colloid Interface Sci., 1979, 72, 488-494.

89 T. Nakamura, M. Hattori, H. Kawasaki, K. Miyamoto, M. Tokita and T. Komai, Phys. Rev. E: Stat. Phys., Plasmas, Fluids, Relat. Interdiscip. Top., 1996, 54, 1663-1668.

90 A. F. Stalder, T. Melchior, M. Müller, D. Sage, T. Blu and M. Unser, Colloids Surf., A, 2010, 364, 72-81.

91 Z. Li, R. F. Giese, C. J. van Oss, J. Yvon and J. Cases, J. Colloid Interface Sci., 1993, 156, 279-284.

92 M. I. Kolte, H. K. Rasmussen and O. Hassager, Rheol. Acta, 1997, 36, 285-302.

93 P. Szabo, Rheol. Acta, 1997, 36, 277-284.

94 B. Mortimer, C. Holland and F. Vollrath, Biomacromolecules, 2013, 14, 3653-3659.

95 Z. Shao and F. Vollrath, Nature, 2002, 418, 741.

96 Y. Yang, C. Dicko, C. D. Bain, Z. Gong, R. M. J. Jacobs, Z. Shao, A. E. Terry and F. Vollrath, Soft Matter, 2012, 8, 9705-9712.

97 A. Ryan, Polymer Processing and Structure Development, Springer, Netherlands, 1998.

98 M. Niesten, J. Krijgsman, S. Harkema and R. Gaymans, J. Appl. Polym. Sci., 2001, 82, 2194-2203.

99 G. Liu, H. Sun, S. Rangou, K. Ntetsikas, A. Avgeropoulos and S.-Q. Wang, J. Rheol., 2013, 57, 89-104.

100 A. Tripathi, P. Whittingstall and G. H. McKinley, Rheol. Acta, 2000, 39, 321-337.

101 P. Erni, M. Varagnat, C. Clasen, J. Crest and G. H. McKinley, Soft Matter, 2011, 7, 10889-10898.

102 N. Kojic, M. Kojic, S. Gudlavalleti and G. McKinley, Biomacromolecules, 2004, 5, 1698-1707.

103 T. Takajima, Advanced Fiber Spinning Technology, Woodhead Publishing, 1994.

104 P. R. Laity, E. Baldwin and C. Holland, Macromol. Biosci., 2018, 180018, DOI: 10.1002/mabi.201800188.

105 F. T. Trouton, Proc. R. Soc. London, Ser. A, 1906, 77, 426-440. 106 C. J. S. Petrie, J. Non-Newtonian Fluid Mech., 2006, 137, 15-23. 107 C. Z. Zhou, F. Confalonieri, M. Jacquet, R. Perasso, Z. G. Li and J. Janin, Proteins: Struct., Funct., Bioinf., 2001, 44, 119-122. 